\title{
Roman Roszko
}

Instytut Slawistyki PAN

Warszawa

\section{ZNACZENIE DWUJĘZYCZNYCH KORPUSÓW W POLSKO- -LITEWSKICH BADANIACH KONFRONTATYWNYCH}

\section{Wstęp}

Opisywane w tym artykule zagadnienia pośrednio nawiązują do publikacji [Roszko 2011: 81-90], w której zgodnie z zasadami teoretycznych badań konfrontatywnych zdefiniowano zakres semantycznej kategorii hipotetyczności, wyróżniono sześć poziomów prawdopodobieństwa i każdemu z nich przypisano odpowiednie polskie i litewskie leksykalne wykładniki tychże znaczeń.

Stawianym w tym artykule zadaniem jest określenie, czy i w jakim stopniu na wyniki badań wpływa wykorzystanie korpusów równoległych, w danym przypad$\mathrm{ku}$ - korpusu polsko-litewskiego. W latach 90. minionego stulecia wspólnie z Danutą Roszko rozpoczęliśmy badania nad kategoriami modalnymi w języku litewskim. Później badania zostały rozszerzone o materiał litewskiej gwary puńskiej w Polsce i język polski. Wyniki tych prac częściowo opublikowano w kilku artykułach i w trzech monografiach [Roszko R. 1993, 2004] i [Roszko D. 2006]. W końcu pierwszej dekady obecnego stulecia przystąpiliśmy do tworzenia korpusów równoległych: bułgarsko-polsko-litewskiego [Dimitrova, Koseska, Roszko R., Roszko D. 2011] oraz polsko-litewskiego. Na podstawie właśnie tych korpusów postanowiono zweryfikować dane uzyskane w sposób tradycyjny (ręczna ekscerpcja).

We wcześniejszych badaniach nad hipotetycznością w językach polskim i litewskim bazowano na cytatach z 11 pozycji (łącznie 22, licząc obie wersje językowe), z których pięć było tłumaczeniami z języka polskiego na litewski, cztery - z języka litewskiego na polski i dwa - z języka rosyjskiego na polski i litewski. Obecnie dzięki wykorzystaniu zasobów eksperymentalnego polsko-litewskiego korpusu równoległego liczba polsko- i litewskojęzycznych tekstów poddanych ekscerpcji znacznie wzrosła. Są to nie tylko wzajemne tłumaczenia, lecz również wiele współcześnie przełożonych utworów z wielu języków, np. niemieckiego, angielskiego, portugalskiego, autorstwa 
Dana Browna, Williama Goldinga, Johna Graya, J. K. Rowling, Paula Coelho, Richarda Bacha, Françoise Sagan, Władimira Sorokina i innych.

Modalna charakterystyka badanego zjawiska powoduje oczywiste ograniczenie analizowanych tekstów do gatunku beletrystyki. W dokumentacji technicznej i aktach prawnych zjawisko modalności jest nieobecne. $\mathrm{W}$ ustawodawstwie unijnym zjawisko hipotetyczności ma charakter sporadyczny, por.:

[1] Dwa pierwsze programy z pewnościq wniosły wartość dodaną do wymiany informacji między administracjami, zaś nowy program na pewno przyczyni się do rozwoju lokalnego i regionalnego poprzez ułatwianie wymiany pomysłów i doświadczeń w różnych dziedzinach, takich jak zatrudnienie, rybołówstwo, rolnictwo, zdrowie, ochrona konsumenta oraz wymiar sprawiedliwości i sprawy wewnętrzne.

Reikia pripažinti, kad dvi pirmosios programos tikrai padejo administravimo institucijoms keistis informacija, o naujoji programa neabejotinai prisidès prie vietos ir regionų vystymosi, nes bus sudarytos geresnès sąlygos keistis idejjomis ir patirtimi įvairiose srityse, pavyzdžiui, užimtumo, žuvininkystès, žemės ūkio, sveikatos, vartotojų apsaugos ir teisingumo ir vidaus reikalų srityse.

W przedstawionym wyżej przykładzie Dyrektywy Rady 2008/118/WE z 16 grudnia 2008 r. można zauważyć polsko-litewskie odpowiedniości: pol. $z$ pewnościa - litew. tikrai i pol. na pewno - litew. neabejotinai. Są to odpowiedniki leksykalne. W tłumaczeniu litewskim dodatkowo zastosowano konstrukcję składniową kooperującą z już wyróżnionym leksemem litew. tikrai: litew. reikia pripažinti, kad ... tikrai.

Szczegółowa analiza ustawodawstwa unijnego wykazała, że formy litewskiego modus relativus nie znajdują zastosowania w tego typu aktach prawnych. Warto jednocześnie zwrócić uwagę na możliwe rozbieżności semantyczne w tłumaczeniach na polski i litewski tych samych aktów prawnych. Okazuje się, że możliwe jest nacechowanie modalne w polskim i brak takiegoż nacechowania w litewskim. Poniższe przykłady (2-3) ukazują na podstawie innej kategorii modalnej - imperceptywności rozbieżną interpretację tekstu wyjściowego:

[2] Sąd ten ustalił, że A. Achughbabian posiada obywatelstwo armeńskie, że zastosowano wobec niego środek w postaci zatrzymania, a następnie środek detencyjny ze względu na nielegalny pobyt i że powołuje on się na to, jakoby art. L. 621-1 Ceseda byt niezgodny z dyrektywą 2008/115, w świetle wykładni przedstawionej w ww. wyroku w sprawie El Dridi.

Šis teismas konstatavo, kad A. Achughbabian yra Armėnijos pilietis, kuris buvo sulaikytas, vèliau suimtas dèl neteisèto gyvenimo šalyje ir kuris teigia, kad Ceseda L. 621-1 straipsnis neatitinka Direktyvos 2008/115, kaip ji aiškinama minètame Sprendime El Dridi. 
[3] Powyższego wniosku nie podważa ani okoliczność przedstawiana przez rząd francuski, jakoby na podstawie okólników kierowanych do instytucji sądowych kary przewidziane przez uregulowanie krajowe rozpatrywane w postępowaniu przed sądem krajowym były rzadko wymierzane z wyjątkiem wypadków, w których nielegalnie przebywająca osoba dopuszcza się, poza wykroczeniem w postaci nielegalnego pobytu, innego wykroczenia, ani okoliczność, również podnoszona przez ten rząd, jakoby A. Achughbabian nie został skazany na taką karę.

Pirma padarytos išvados nepaneigia nei Prancūzijos vyriausybės nurodyta aplinkybė, kad pagal teisèsaugos institucijoms išsiųstus aplinkraščius nagrinėjamuose nacionalinės teisės aktuose nustatytos bausmės, išskyrus atvejus, kai asmuo be neteisèto buvimo šalyje padare dar ir kitą baudžiamąjį nusižengimą, retai skiriamos, nei tai, kad, kaip taip pat nurode ši vyriausybė, A. Achughbabian minètos bausmès nebuvo skirtos.

W polskich zdaniach (2-3) trzykrotnie pojawia się wykładnik jakoby, który zajmuje w zdaniu podrzędnym syntaktyczną pozycję łączącą z członem nadrzędnym i jednocześnie nadaje członowi podrzędnemu odcień nierzeczywistości, niepewności, nieprawdopodobieństwa. W wersji litewskiej nie obserwuje się analogicznego zjawiska. Nie zastosowano żadnego wykładnika leksykalnego, morfologicznego ani syntaktycznego, który by wskazywał na przekaz treści modalnych imperceptywnych.

\section{Semantyczna kategoria hipotetyczności}

Przyjęta w pracy [Roszko 2011: 81-90] definicja znaczeń hipotetycznych jest zgodna z teoretycznymi założeniami hipotetyczności zawartymi w Gramatyce Konfrontatywnej Bułgarsko-Polskiej [Maldžieva 2003].

Przyjmuje się, że hipotetyczność jest jedną z kategorii charakterystycznych dla języka naturalnego i że wyraża subiektywny stosunek nadawcy (mówiącego) do przedstawianych przez siebie stanów i zdarzeń (wyrażanie subiektywnego stosunku nadawcy jest równoznaczne z obecnością funktora możliwości w semantycznej strukturze zdania). Hipotetyczność to kategoria zdaniowa. Może być wyrażana na poziomach: leksykalnym, morfologicznym i syntaktycznym. Cechą charakterystyczną hipotetyczności jest stopniowalność prawdopodobieństwa, przedstawiana w opisie jako oś o parametrze prawdopodobieństwa, którego wartości oscylują między pozycjami skrajnymi: fałszu (0) i prawdy (1). W pracy Danuty Roszko [2006] na skali prawdopodobieństwa znajdowała się wielkość 1/2, która miała odzwierciedlać idealnie centralne położenie na osi, związane z użyciem morfologicznego wykładnika hipotetyczności dla języka litewskiego i litewskiej gwary puńskiej. W Gramatyce Konfrontatywnej Bułgarsko-Polskiej [Maldžieva 2003] nie wyróżnia się wykładników morfologicznych (jest to konsekwencja struktur języków poddanych analizie), tym samym wartość odpowiadająca stopniu zrównania prawdopodobieństwa zdania $\mathrm{P}(\mathrm{x})$ i jego negacji $\sim \mathrm{P}(\mathrm{x})$ nie została uwzględniona. 


\section{Wykładniki modalności hipotetycznej w językach polskim i litewskim}

Wykładniki semantycznej kategorii hipotetyczności bazują na środkach: leksykalnych (w obu językach), morfologicznych (tylko język litewski) i syntaktycznych (typowe dla obu języków). Szerzej na ten temat m.in. w [Roszko D. 2006].

Funkcjonowanie form modus relativus powoduje, że w języku litewskim na poziomie formalnym można konsekwentnie rozróżniać fragmenty tekstu nacechowanego hipotetycznie i fragmenty nienacechowane hipotetycznie. Brak morfologicznych wykładników hipotetyczności w polskim sprawia, że wykorzystanie tylko środków leksykalnych i syntaktycznych nie gwarantuje stuprocentowej pewności odczytania przez odbiorcę w tekście granic treści nacechowanych modalnie hipotetycznie. Zazwyczaj ze względów stylistycznych unika się dublowania środków leksykalnych.

\subsection{Wykładniki leksykalne hipotetyczności}

Przedstawiana tu analiza zostaje zawężona do wykładników leksykalnych w obu językach. W tabeli 1 podano typowe wykładniki modalności hipotetycznej dla obu języków, zestawione w sześć grup o rosnącym stopniu prawdopodobieństwa.

Tabela 1. Wykładniki leksykalne modalności hipotetycznej w językach polskim i litewskim

\begin{tabular}{|c|l|l|}
\hline Grupa & \multicolumn{1}{|c|}{ Język polski } & \multicolumn{1}{c|}{ Język litewski } \\
\hline I & może i & gal ir \\
\hline II & a może i, może zresztą & o gal ir \\
\hline III & a może & o gal \\
\hline IV & $\begin{array}{l}\text { chyba, może jednak, może rzeczywiście, może } \\
\text { naprawdę, przypadkiem, a może faktycznie }\end{array}$ & $\begin{array}{l}\text { gal, turbūt, nebent, gal tikrai, } \\
\text { gal vistiek, o gal faktiškai }\end{array}$ \\
\hline V & $\begin{array}{l}\text { być może, może, pewnie, zapewne, tak } \\
\text { myślę, moim zdaniem, prawdopodobnie, } \\
\text { przypuszczalnie, ewentualnie, możliwe, widać, } \\
\text { wydaje się, zdaje się, snadź, bodaj/bodajże } \\
\text { (sporadycznie w znaczeniu hipotetyczności) }\end{array}$ & $\begin{array}{l}\text { galbūt, titikimai, eventualiai, } \\
\text { man rodos, taip manau, pagal } \\
\text { mane, pasirodo, atrodo, rodos, } \\
\text { berods, man atrodo, galimas } \\
\text { daiktas, manyčiau, tikrai, } \\
\text { faktiškai, rasi, matyt }\end{array}$ \\
\hline \multirow{2}{*}{ VI } & $\begin{array}{l}\text { najpewniej, najprawdopodobniej, moim } \\
\text { zdaniem, jak widać, bez wątpliwości, } \\
\text { jak sądzę, jak przypuszczam, jak mi się, } \\
\text { zdaje, na pewno, niewątpliwie, widocznie, } \\
\text { najwidoczniej, bez wątpienia, niechybnie, } \\
\text { nieomylnie, na mur, mur beton, iście, } \\
\text { doprawdy, murowanie, jako żywo, ani chybi } \\
\text { (ni chybi) }\end{array}$ & $\begin{array}{l}\text { tikriausia, tikriausiai, } \\
\text { veikiausiai, greičiausiai, } \\
\text { mano galva, be abejonès, kaip } \\
\text { manau, kaip man atrodo, man } \\
\text { panašiausia, iš tikro, iš tikrųjų, } \\
\text { tikras dalykas, žinoma }\end{array}$ \\
\hline
\end{tabular}

Przedstawione w tabeli 1 wykładniki są rezultatem badań prowadzonych na podstawie eksperymentalnego korpusu polsko-litewskiego. Wykaz wykładników 
wyróżnionych w badaniach bez wykorzystania zasobów korpusowych był uboższy. Praktycznie w badaniach tradycyjnych (bez wykorzystania korpusu) zidentyfikowano typowe dla obu języków środki leksykalne (tj. te o najwyższej frekwencji, np. pol. chyba, litew. gal) i te, które wykazują duże formalne podobieństwo, np. pol. a może i, litew. o gal ir. Dopiero bogaty materiał korpusowy ujawnił inne paralelne pary wykładników hipotetyczności, niedostrzeżone ze względu na niską częstotliwość użycia podczas ręcznej ekscerpcji materiału, np. pol. iście, nieomylnie, doprawdy, ani/ni chybi, litew. rasi, manyčiau, mano galva. Szczegółowa analiza przyczyn dysproporcji w liczbie zidentyfikowanych dla obu języków wykładników leksykalnych doprowadziła do konstatacji, że materiał badań ograniczony tylko do 11 równoległych polskich i litewskich pozycji, w większości bazujący na wzajemnych tłumaczeniach ( 9 z 11 pozycji) i tłumaczeniach z rosyjskiego (dwie pozycje), nie był wystarczający do uzyskania obecnie satysfakcjonujących rezultatów. Minikorpus eksperymentalnie utworzony na podstawie tych wcześniejszych 11 pozycji poddano osobnej analizie. Jak się okazało, rezultaty badań niewiele odbiegały od wcześniej uzyskanych. Przyczyn braku istotnych różnic upatruje się więc w charakterze powieści pierwotnie wybranych do analizy oraz w typowej dla tamtego okresu specyfice języka, ta uwaga szczególnie dotyczy utworów litewskich i rosyjskich powstałych w okresie radzieckim.

Wymuszona obiektywnymi przyczynami wyrywkowość tradycyjnej ekscerpcji w przypadku obszernego jak na tego typu badania materiału (11 powieści) była rzeczą naturalną. W związku z powyższym nie mogły być sformułowane daleko idące wnioski dotyczące samej frekwencji wykładników, jak i szczegółowej listy ekwiwalentów polsko-litewskich. Dlatego między innymi we wcześniejszych badaniach zwracano uwagę na rozmyte granice między poszczególnymi grupami. Na przykład uważano, że wykładniki grupy IV mogły być wymiennie używane również dla wyrażenia stopnia prawdopodobieństwa charakterystycznego dla grup sąsiednich, czyli tu - III lub V. Materiał korpusowy potwierdził słuszność tego założenia. Jednak skala samego zjawiska okazała się mniejsza od zakładanej. Dokładne dane statystyczne wykazały, że zjawisko rozmycia granic jest związane z wielkością maksymalnie 9\% (średnio - poniżej 5\%) wszystkich zanotowanych przypadków. Poniżej na przykładzie pary pol. chyba i litew. turbūt zostanie zilustrowana wspomniana zależność.

W 68\% przypadków wykorzystania polskiej formy chyba ${ }^{1}$ odpowiada jej litewska postać turbüt. Pozostałe stwierdzone pary charakteryzują się następującymi parametrami:

$$
\begin{array}{ll}
\text { pol. chyba - litew. nebent } & -23 \%, \\
\text { pol. chyba - litew. gal } & -5 \%, \\
\text { pol. chyba - litew. rasi } & -2 \%, \\
\text { pol. chyba - litew. matyt } & -1 \% .
\end{array}
$$

\footnotetext{
${ }^{1}$ Polska forma chyba w znaczeniu hipotetycznym została odnotowana w korpusie 1964 razy.
} 
Brakujący w wyliczeniach procent obejmuje pozostałe polsko-litewskie odpowiedniości, ich pominięcie nie rzutuje na wyniki końcowe. Tabela 2 przedstawia szczegółowe wyniki analizy korpusowej.

Tabela 2. Typowe litewskie odpowiedniki polskiego chyba (grupa IV) na podstawie zasobów eksperymentalnego korpusu polsko-litewskiego

\begin{tabular}{|l|l|c|c|}
\hline $\begin{array}{c}\text { Wykładnik } \\
\text { polski }\end{array}$ & \multicolumn{1}{|c|}{$\begin{array}{c}\text { Ekwiwalent } \\
\text { litewski }\end{array}$} & Procent & Grupa \\
\hline chyba & turbūt & $68 \%$ & IV \\
\hline chyba & nebent & $23 \%$ & IV \\
\hline chyba & gal & $5 \%$ & IV \\
\hline \multicolumn{2}{|r|}{ Razem } & $=96 \%$ & IV \\
\hline chyba & rasi & $<2 \%$ & V \\
\hline chyba & matyt & $<1 \%$ & V \\
\hline \multicolumn{2}{|r|}{ Razem } & $=<3 \%$ & V \\
\hline
\end{tabular}

Rozmycie granic między poszczególnymi grupami prawdopodobieństwa zostało potwierdzone w stopniu niższym od 3\%. W tym zestawieniu charakterystyczne jest tylko naruszenie granicy między grupą IV i V. Nie odnotowano ani jednego przypadku zamiennego zastosowania wykładników z grupy III i IV.

$\mathrm{W}$ związku z powyższymi danymi interesujące z naukowego punktu widzenia wydaje się ujawnienie najczęstszych litewsko-polskich par dla wyjściowej litewskiej formy turbū $t^{2}$. Okazuje się, że tych par jest stosunkowo niewiele. Najczęściej notowaną w korpusie parą jest spodziewana odpowiedniość litew. turbūt - pol. chyba (96\%). Drugą ważną parę tworzy z litew. turbūt pol. bodaj (3\%), por. tabela 3.

Tabela 3. Typowe polskie odpowiedniki litewskiego turbūt (grupa IV) na podstawie zasobów eksperymentalnego korpusu polsko-litewskiego

\begin{tabular}{|l|c|c|c|}
\hline $\begin{array}{c}\text { Wykkadnik } \\
\text { litewski }\end{array}$ & $\begin{array}{c}\text { Ekwiwalent } \\
\text { polski }\end{array}$ & Procent & Grupa \\
\hline turbūt & chyba & $96 \%$ & IV \\
\hline \multicolumn{2}{r|r|}{ Razem } & $=96 \%$ & IV \\
\hline turbūt & bodaj & $3 \%$ & V \\
\hline \multicolumn{2}{r|}{ Razem } & $=3 \%$ & V \\
\hline
\end{tabular}

${ }^{2}$ Litewska forma turbūt w znaczeniu hipotetycznym została odnotowana w korpusie 1355 razy. 
Zaskakujący również i w tym zestawieniu jest fakt, że ulega naruszeniu granica między IV i V grupą. Jak się okazuje, a potwierdzają to również inne nieprzedstawiane tu dane korpusowe, wykładniki grupy IV nigdy nie zostają zastosowane dla wyrażenia znaczeń grupy III. Może to oznaczać, że różnica prawdopodobieństwa wyrażanego wykładnikami grup III i IV jest na tyle istotna, że nie może dochodzić do wymiennego użycia wykładników tychże grup. Natomiast różnica w stopniu wyrażenia prawdopodobieństwa między grupami IV i V jest zdecydowanie niższa, co potwierdza sporadyczne, zamienne wykorzystanie środków obu grup dla zaznaczenia ustalonej wartości prawdopodobieństwa.

Analiza korpusowa, jak to już wcześniej nadmieniono, ujawniła kilka kolejnych wykładników hipotetyczności. Jednym z nich jest litewskie rasi, które zapewne wywodzi się z formy 2. osoby czasu przyszłego czasownika litew. rasti 'znaleźć'. Poniżej dwa przykłady ilustrujące użycie litewskiej formy rasi w tekście wraz z równoległymi zdaniami polskimi.

[4] Kuris podraug bjaurisi savo geidimo objektu ir kraustosi iš galvos dèl jo, ir atiduotų dèl jo gyvybę, rasi, prilygdamas jausmais Romeo ir Džiuljetai...

Który jednocześnie brzydzi się obiektu swej pożądliwości i szaleje za nim i gotów jest narazić dla niego życie dorównując, być może, uczuciom Romea dla Julii...

[5] Model, ale chyba naturalnej wielkości.

Modelis, bet, rasi, natūralaus dydžio.

Częstotliwość użycia tej formy jest stosunkowo niska. W eksperymentalnym korpusie polsko-litewskim odnotowano tylko 362 użycia wykładnika hipotetyczności rasi. W odróżnieniu od wielu innych wykładników tej litewskiej formie nie odpowiada wyraźnie tylko jeden polski wykładnik. Litewskie rasi tworzy pary z następującymi polskimi odpowiednikami: pol. być może (25\%), może (33\%), bodaj (33\%) i chyba (9\%). Pierwsze trzy odpowiedniki zaliczono, podobnie jak litew. rasi, do grupy V. Tylko jeden polski odpowiednik chyba należy do grupy IV.

\section{Konfrontacja danych korpusowych i słownikowych}

Niejednokrotnie już podkreślano, że analiza zasobów korpusowych może pozytywnie wpłynąć na jakość dwujęzycznych słowników. Na potrzeby tego artykułu przeprowadzono test spójności polegający na zestawieniu wyników a) analizy korpusowej dla wybranego litewskiego wykładnika hipotetyczności z b) formami podawanymi w litewsko-polskim słowniku PolLit'as [Vaitkevičiūtè 2003]. Nieprzypadkowo wybrano wersję elektroniczną słownika liczącego około 100000 haseł. Wyszukiwanie w elektronicznym źródle jest zdecydowanie szybsze i skuteczniejsze od wertowania kilkusetstronicowej wersji drukowanej tegoż słownika. Wyniki zestawienia przedstawiono w tabeli 4. 
Tabela 4. Spójność danych korpusowych i słownikowych na przykładzie litewskiego wykładnika hipotetyczności rasi (grupa V - 91\% użyć, wtórnie - grupa IV $-9 \%$ użyć)

\begin{tabular}{|c|c|c|c|c|c|}
\hline \multirow[b]{2}{*}{ Lp. } & \multicolumn{2}{|c|}{ Dane słownikowe } & \multicolumn{2}{|c|}{ Dane korpusowe } & \multirow[b]{2}{*}{ Grupa } \\
\hline & $\begin{array}{l}\text { Litewskie } \\
\text { synonimy }\end{array}$ & $\begin{array}{c}\text { Polskie } \\
\text { odpowiedniki }\end{array}$ & Litewskie synonimy & $\begin{array}{c}\text { Polskie } \\
\text { odpowiedniki }\end{array}$ & \\
\hline 1. & $\begin{array}{l}\text { galbūt } \\
\text { matyt }\end{array}$ & & $\begin{array}{l}\text { galbūt } \\
\text { matyt }\end{array}$ & $\begin{array}{l}\text { może (33\%), } \\
\text { bodaj (33\%), } \\
\text { być może (25\%) }\end{array}$ & V \\
\hline 2. & & & $\begin{array}{l}\text { itikimai, eventualiai, man } \\
\text { rodos, taip manau, pagal } \\
\text { mane, pasirodo, atrodo, } \\
\text { rodos, berods, man } \\
\text { atrodo, galimas daiktas, } \\
\text { manyčiau, tikrai, faktiškai }\end{array}$ & & V \\
\hline 3. & & chyba & & chyba $(9 \%)$ & IV \\
\hline 4. & & pewnie & & & $\mathrm{V}$ \\
\hline 5. & turbūt & & & & IV \\
\hline 6. & $\begin{array}{l}\text { tikriausiai, } \\
\text { be abejonės }\end{array}$ & & & & VI \\
\hline
\end{tabular}

Omówienie danych z tabeli 4.

Kwestia pierwsza - litewskie synonimy

Analiza haseł słownikowych wykazała pięć synonimów dla wyjściowego w eksperymencie litewskiego rasi. W zestawieniu z danymi korpusowymi tylko dwie z pięciu form są trafne (poz. 1): galbūt i matyt (grupa V). Pozostałe trzy formy litew. turbūt (poz. 5), tikriausiai, be abejones (poz. 6) - synonimiczne zdaniem autora słownika - są sprzeczne z wynikami analizy korpusowej, należą bowiem do grup IV i VI. Za właściwe uznano by wskazanie dowolnej litewskiej formy podanej w poz. 1 i 2.

Kwestia druga - polskie odpowiedniki

O ile trafność wskazania litewskich synonimów była na poziomie 40\% (zgodność dwóch z pięciu form), o tyle polskie odpowiedniki osiągnęły znikomy procent zgodności. W słowniku wszak wskazano jeden polski odpowiednik korespondujący $\mathrm{z}$ właściwą dla litewskiego rasi grupą $\mathrm{V}$ - pol. pewnie (poz. 4), jednakże dane korpusowe nie potwierdzają ani jednego przypadku korespondencji pol. pewnie i litew. rasi. Drugi (z dwóch) polski odpowiednik (chyba, poz. 3, grupa IV) litewskiego rasi odzwierciedla jedynie 9\% przypadków zgodności odnotowywanej w zasobach korpusowych.

Na podstawie danych korpusowych przykładowe hasło słownikowe dla litewskiego rasi mogłoby przyjąć poniższą postać:

rasi $\quad(\mathrm{Mm}: \mathrm{H})$

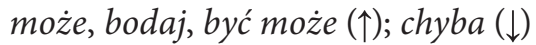

gdzie Mm - modalność możliwościowa 

$\mathrm{H}$ - hipotetyczność
( $\uparrow$ - odpowiednik o wysokiej frekwencji
$(\downarrow)$ - odpowiednik o niskiej frekwencji.

\section{Wpływ języka oryginału na polsko-litewskie odpowiedniości}

W ramach innego eksperymentu oddzielnie analizowano materiał korpusowy zawężony do tekstów równoległych, w których językiem wyjściowym był: a) litewski, b) polski, c) język trzeci.

Wyniki zestawien (b-c) były bardzo zbliżone i w pewnym stopniu różniły się od wniosków wypływających z zestawienia (a). Zaobserwowano bowiem niższe alternatywne zróżnicowanie polskich odpowiedników w parach tekstów litewskich i ich polskich przekładów. Oznacza to, że liczba ekwiwalentnych par litewsko-polskich była mniejsza w podkorpusie (a), niż to zaobserwowano w obu pozostałych podkorpusach (b-c). Charakterystyczny jest również fakt, że formalna postać litewskich wyrażeń złożonych miała istotny wpływ na wybór polskiego odpowiednika, np. litew. o gal faktiškai - pol. a może faktycznie, litew. be abejonés - pol. bez watpliwości. Niekiedy takie podejście skutkowało zmianą znaczenia hipotetycznego, np. litew. gal vistiek (IV grupa) - pol. może zreszta (II grupa).

W świetle powyższych stwierdzeń spodziewalibyśmy się analogicznego zjawiska w grupie (b) - mianowicie wpływu płaszczyzny formalnej języka polskiego jako wyjściowego na postać wykładnika w przekładzie na język litewski. Materiał korpusowy nie potwierdza takiego schematu.

W tłumaczeniach z języka litewskiego na polski zwrócono też uwagę na sposób oddania morfologicznych wykładników hipotetyczności, charakterystycznych - jak wiadomo - tylko dla języka litewskiego. Otóż samodzielne wystąpienie litewskiej formy modus relativus w znaczeniu hipotetycznym nie pociągało za sobą żadnych konsekwencji w polskim tłumaczeniu, por.:

[6a] Atsiprašau! Būsiu pamiršęs prisegti maketą prie ankstesnio savo laiško. Siunčiu dabar.

Przepraszam, lecz zapomniałem podpiąć makietę do wcześniejszego listu. Posyłam teraz.

[6b] Przepraszam! Najwyraźniej zapomniałem podpiąć makietę do wcześniejszego listu. Posyłam teraz.

W zdaniu [6b] podano spodziewany polski wariant litewskiego zdania [6a]. Kooperacja leksykalnych i morfologicznych wykładników w języku litewskim nie sprawiała tłumaczom trudności w hipotetycznym nacechowaniu polskiego tekstu, por.

[7] Sauliau, greičiausiai prieš dvi ar tris dienas būsiu pamiršusi išgerti tabletę.

Saulius, najprawdopodobniej przed dwoma czy trzema dniami zapomniałam o tabletce. 


\section{Wnioski}

Konfrontacja obu opisanych metod badawczych ujawniła przewagę współczesnych - szeroko wykorzystujących dwujęzyczne zasoby korpusowe - badań nad podejściem tradycyjnym, w którym ekscerpcja odbywała się na podstawie skromniejszego materiału i siłą rzeczy była czasochłonna.

Wykorzystanie zasobów korpusowych spowodowało, że liczba ujawnionych wykładników hipotetyczności w obu językach wzrosła. Ponadto granice między poszczególnymi grupami wykładników stały się bardziej wyraziste i oczywiste. Potwierdzona została możliwość wykorzystania wykładników konkretnej grupy dla wyrażenia znaczeń grup sąsiednich. Jednocześnie stwierdzono, że nie jest to zjawisko tak oczywiste, jak wcześniej się tego spodziewano (tj. w badaniach tradycyjnych bez użycia dwujęzycznych korpusów).

Oddzielna analiza zasobów korpusowych w podziale na materiał będący a) wzajemnymi przekładami polsko-litewskimi (tj. z języka polskiego na litewski i na odwrót) oraz b) przekładami na języki polski i litewski z języków trzecich nie wpływa znacząco na liczbę i różnorodność zastosowanych wykładników leksykalnych w interesujących nas językach. Może to świadczyć o wysokiej kompetencji tłumaczy. Formalne podobieństwo niektórych wykładników polskich i litewskich nie ma wpływu na wybór formy w języku docelowym. Jednak gdy grupa wzajemnych tłumaczeń polsko-litewskich zostaje rozbita na dwie, wówczas okazuje się, że przekłady z języka litewskiego na polski charakteryzuje pewien ascetyzm w doborze polskich ekwiwalentów. Również w niektórych tłumaczeniach z litewskiego na polski obserwuje się całkowite pomijanie znaczeń ( $w$ tym też hipotetycznych) wynikających $z$ użycia litewskich form modus relativus (morfologiczny wykładnik modalności imperceptywnej, hipotetycznej, admiratywnej, konkluzywnej...). W kilku przypadkach zaobserwowane rozbieżności między oryginałem litewskim a interpretacją w przekładzie polskim mogą sugerować różny od deklarowanego kierunek tłumaczenia (nie bezpośrednio z litewskiego na polski, lecz za pośrednictwem rosyjskojęzycznego przekładu). Potwierdzenie tej hipotezy wymaga jednak utworzenia trójjęzycznego korpusu polsko-litewsko-rosyjskiego dla wybranych utworów, pozwalającego na systematyczne i konsekwentne badania w tym kierunku.

\section{LITERATURA}

Dimitrova L., Koseska-Toszewa V., Roszko D., Roszko R., 2010, Application of Multilingual Corpus in Contrastive Studies (on the example of the Bulgarian-Polish-Lithuanian Parallel Corpus), „Cognitive Studies | Études Cognitives”, 10, s. 217-239.

Dimitrova L., Koseska-Toszewa V., Roszko D., Roszko R., 2011, Bulgarian-Polish-Lithuanian Corpus - Recent Progress and Application, [w:] Majchráková D., Garabík R. (red.), Natural Language Processing, Multilinguality, Bratislava, s. 30-43. 
LKŽ 2008, Lietuvių kalbos žodynas, wariant elektroniczny, pierwsze wydanie (2005), ostatnia aktualizacja (2008): http://www.lkz.lt

Maldžieva V., 2003, Modalność: hipotetycznossć, irrealność, optatywność i imperatywność, warunkowość, Gramatyka Konfrontatywna Bułgarsko-Polska, t. 6, cz. 3, Warszawa.

Roszko D., 2006, Funkcjonalne odpowiedniki litewskiego perfectum w litewskiej gwarze puńskiej i w języku polskim, Warszawa.

Roszko D., Zagadnienia kwantyfikacyjne i modalne w litewskiej gwarze puńskiej (na tle literackich języków polskiego i litewskiego), Warszawa [w druku].

Roszko R., 1993, Wykładniki modalności imperceptywnej w języku polskim i litewskim, Warszawa.

Roszko R., 2004, Semantyczna kategoria określoności/nieokreśloności w języku litewskim (w zestawieniu z językiem polskim), Warszawa.

Roszko R., 2011, Leksykalne wykładniki hipotetyczności w językach polskim i litewskim, „Acta Baltico-Slavica”, 35, s. 81-90.

Vaitkevičiūtè V., 2003, Kompiuterinis lenkų-lietuviu, lietuvių-lenkų žodynas PolLit'as (wersja elektroniczna słownika: V. Vaitkevičiūtè, Didysis lenkų-lietuvių žodynas, Myros Martišienès vertèjų biuro, 2003).

\section{THE MEANING OF BILINGUAL CORPORA IN THE POLISH-LITHUANIAN CONTRASTIVE STUDIES}

\section{SUMMARY}

In his article, the author compares and contrasts the results of his own research on the hypothetical modality in Polish and Lithuanian: a) carried out together with Danuta Roszko, using the traditional method (without use of bilingual corpora in the 90s); b) with use of parallel Polish-Lithuanian corpora resources.

As for the contrast of the two methods, special attention has been drawn to the lexical exponents singled out.

The use of the corpora resources resulted in the fact that the number of exponents of hipothetical modality singled out in the two languages has slightly risen. Moreover, the borders between the corresponding groups of exponents have become more distinct and obvious. There has been confirmed a possibility of using the corresponding groups of exponents to express the meanings of the adjacent groups. The conclusion has been drawn that this phenomenon is as obvious now as it was earlier expected (in studies without use of bilingual corpora).

The separate analysis of corpora resources with the division into the material being a) mutual Polish-Lithuanian translations (i.e. from Polish into Lithuanian and vice versa) and b) translations into Polish and Lithuanian from third languages (here: from German, English or Russian) does not significantly influence the number and diversity of the lexical exponents applied in the two languages. This fact proves 
a high competence of the translators. The formal resemblance of some of the Polish and Lithuanian exponents does not have a significant influence on which form to choose in the target language.

In the translations from Polish into Lithuanian, part of the lexical exponents are conveyed with morphological exponents (lack of such in Polish). The hypothetical modality understated in Polish is sometimes clarified in translations into Lithuanian with the help of morphological forms. In some translations from Lithuanian into Polish the total omission of meanings (also the hypothetical) can be noticed, which results from applying the Lithuanian modus relativus forms. In several cases where some Lithuanian-Polish divergences in translations from Lithuanian into Polish have been noticed, a preliminary comparison of a Lithuanian original material and its translation into Russian can suggest that despite the confirmed direction of translation (from Lithuanian into Polish), it can indeed be a translation from Russian into Polish. However, proving this hypothesis requires the establishing of a trilingual Polish-Lithuanian-Russian corpora for the selected material to allow systematic and consistent studies in this direction.

The author gives statistical data for the Polish-Lithuanian lexical exponents of hypothetical modality to distinguish between the mutual translations (Polish-Lithuanian) and those of third languages.

\author{
О РЕЗУЛЬТАТАХ ИСПОЛЬЗОВАНИЯ РЕСУРСОВ \\ ДВУЯЗЫЧНОГО КОРПУСА НА ПРИМЕРЕ ПОЛЬСКО- \\ -ЛИТОВСКОГО СОПОСТАВИТЕЛЬНОГО ИССЛЕДОВАНИЯ
}

\title{
PEЗЮME
}

В статье автор сопоставляет результаты двух научных исследований по гипотетической модальности - в польском и литовском языках: (а) традиционных исследований и (б) современных, в которых используются цифровые ресурсы (здесь экспериментальный польско-литовский параллельный корпус).

Описание гипотетической категории модальности основывается на методе теоретического сопоставления естественных языков с использованием так называемого языка-посредника (tertium comparationis). Выделяется 6 степеней вероятности (здесь возможности) и соответственно - 6 параллельных групп средств выражения гипотетичности в обоих языках.

Использование параллельного корпуса в исследовании гипотетичности приводит к новым фактам. Количество показателей гипотетичной модальности оказывается несколько выше, чем это было установлено в ходе традиционного исследования (вручную). Следующее, цифровые ресурсы подтверждают предложение об использовании показателей данной группы вероятности/возмож- 
ности для выражения значений соседних групп, хотя во время проведения традиционных исследований ожидалось бо́льшее число использования средств одной группы для выражения соседних степеней вероятности.

Проведенный отдельно анализ ресурсов корпуса, материал которых выбран по исходному языку оригинала: (корпус А) литовского языка, (корпус Б) польского языка, (корпус В) другого языка (напр. английского, португальского, немецкого, русского) показал, что только в одном случае установленных польско-литовских эквивалентных групп показателей гипотетичности заметно меньшее количество и разновидность тех же групп. Речь идет о корпусе A, в котором исходным для перевода является литовский язык.

Установлено также, что в переводе с литовского на польский язык литовские формы модус релятивус (modus relativus) обычно не переводятся. В таких случаях польский перевод теряет исконную модальную характеристику, разве что в оригинале формам modus relativus cопутствуют другие лексические или синтаксические показатели модальности. В некоторых случаях отсутствие семантического соответствия между литовским оригиналом и польским текстом допускает предпосылку непосредственного перевода с русского (а не литовского) на польский язык. Чтобы это доказать, нужен трехъязычный литовско-польско-русский корпус (ограниченный избранными исконно литовскими произведениями и их переводами на польский и русский языки).

В статье корпусные данные сопоставляются с литовско-польским словарем. Оказывается, что предлагаемые автором словаря литовско-польские соответствия лишь в небольшой степени подтверждаются цифровыми ресурсами польско-литовского корпуса.

Słowa kluczowe: język polski, język litewski, modalność hipotetyczna, badania konfrontatywne, równoległy korpus polsko-litewski.

Key words: Lithuanian, Polish, contrastive studies, hypothetical modality, parallel Polish-Lithuanian corpus.

Ключевые слова: польский язык, литовский язык, сопоставление языков, гипотетическая категория модальности, двуязычный польско-литовский корпус. 